\title{
Mouse Models to Study Systemic Amyloidoses: Is Prion-Like Transmission a Common Pathogenic Mechanism?
}

\author{
Keiichi Higuchi et al.* \\ Department of Aging Biology, Institute on Aging and Adaptation, Shinshu University \\ Graduate School of Medicine, \\ Japan
}

\section{Introduction}

The amyloidoses are a group of protein-misfolding disorders characterized by the accumulation of amyloid fibrils formed from a variety of proteins. Currently, twenty- eight different kinds of human and animal proteins, in intact or fragmented forms, have been found to be associated with pathological disorders such as Alzheimer's disease, type II diabetes, prion diseases, dialysis-related amyloidosis, and various familial, senile and sporadic amyloidosis (Sipe et al., 2010; Benson et al 2008). Amyloidoses have been divided into two major classes: 1) systemic and 2) localized amyloidoses. In systemic amyloidoses, precursor proteins circulating in the blood associate to form amyloid fibrils that are then deposited throughout the body. For example, immunoglobulin light chains form deposits in patients with myeloma in AL amyloidosis. In reactive AA amyloidosis, serum amyloid A (SAA) protein forms deposits in patients with chronic inflammation, and transthyretin (TTR) forms deposits in patients with familial amyloid polyneuropathy (FAP) and senile systemic amyloidosis (SSA). Patients on long-term hemodialysis develop dialysis-related amyloidosis (DRA) due to the deposition of amyloid fibrils $\left(A \beta_{2} \mathrm{M}\right)$ of $\beta_{2}$-microglobulin $\left(\Omega_{2} \mathrm{~m}\right)$. In contrast to systemic amyloidosis, precursor proteins produced in local organs deposit in one particular area of the body in various localized amyloidoses.

In mice, apolipoprotein A-II (apoA-II) in serum high density lipoproteins (HDL) forms amyloid fibrils (AApoAII) in age-associated systemic amyloidosis (senile AApoAII amyloidosis). AA amyloidosis, known as reactive or secondary amyloidosis associated with inflammation, is generally recognized as the predominant form of systemic amyloidosis that occurs in humans, mice, domestic animals and many species in the animal kingdom. These amyloidoses are characterized by the systemic deposition of extracellular fibrils composed of apoA-II in AApoAII amyloidosis or SAA (serum AA) in AA amyloidosis, primarily in the spleen, liver, heart, kidney, vessels walls, and to a lesser extent in other organs. In most

"Xiaoying Fu, Pengyao Zhang, Jinko Sawashita, Beiru Zhang, Jinze Qian, Wang Yaoyong and Masayuki Mori

Department of Aging Biology, Institute on Aging and Adaptation, Shinshu University Graduate School of Medicine, Japan 
species, AApoAII and AA amyloidosis occurs sporadically and is associated with aging (AApoAII amyloidosis) and chronic inflammation (AA amyloidosis). However, intriguing recent data suggest that both AApoAII and AA amyloidoses could be transmitted by a prion-like infectious process through a seeding-nucleation mechanism (Qian et al., 2010; B. Zhang et al., 2008). In these amyloidoses, AApoAII and AA amyloid fibrils, abnormal forms of the host serum proteins (apoA-II and SAA), induce conformational changes in apoA-II and SAA to form AApoAII and AA fibrils, and this causes detectable phenotypes or diseases in affected individuals. Recently, Aß amyloid fibrils in Alzheimer's disease and intracellular amyloid fibril-like aggregated proteins were postulated to work as seeds for propagation of mis-folded and pathologic protein structures in various neurodegenerative disorders, including Huntington's disease, Parkinson's disease and tauopathies (Aguzzi et al., 2009; Brundin et al., 2010).

The prion-like transmission of amyloid fibrils or fibril-like materials, which could play an important role in the propagation of pathological events in systemic amyloidosis, will be discussed here.

\section{Transmission of mouse senile AApoAll amyloidosis}

Several senescence-prone inbred strains of mice (SAMP strains) have been developed with accelerated senescence, a shorter life span and various age-associated disorders and pathologic changes. These SAMP strains include SAMP1, SAMP6, SAMP8 and SAMP10. An accelerated senescence-resistant strain (SAMR1) has also been generated to serve as a control for the SAMP strains (Takeda et al., 1981; Higuchi et al., 1999). Severe senile amyloidosis is a characteristic age-associated disorder in the SAMP1 and SAMP10 strains, making them a valuable model to investigate amyloidosis pathogenesis and to assist in the development of effective therapeutic modalities. We identified apoA-II, a normal constituent of serum HDL, as the amyloid protein responsible for mouse senile amyloidosis in the SAMP1 strain, and the amyloid fibril was named AApoAII (Higuchi et al., 1983; Yonezu et al 1986; Higuchi et al. 1986). Recently we found that there was prion-like transmission in mouse AApoAII amyloidosis (Higuchi et al., 1998; Xing et al., 2001). Here, a brief history and the pathobiology of mouse AApoAII amyloidosis in SAMP1 and its related strains is described, followed by a discussion of AApoAII amyloidosis transmission.

\subsection{Pathology of mouse AApoAll amyloidosis}

Amyloid fibril deposition in aged SAMP1 mice is systemic and all organs except brain parenchyma are involved (Takeshita et al., 1982). The earliest AApoAII deposits are seen in the primary and secondary papillae of the tongue, the lamina propria and submucosa of the small intestine, the alveolar septa of the lungs and the squamous-glandular junction of the stomach. With advancing age, AApoAII deposits extend into the collecting tubules in the papillae of the kidneys, the perimedullary zone of the adrenal cortex, heart and skeletal muscle interstitium, thyroid gland interstitium, the papillary layer of the dermis, the testis interstitium, the corpora lutea, the atretic follicle and the ovarian interstitium, around the portal veins and in the spaces of Disse in the periportal sinusoid of the liver, the marginal zone around the lymphoid follicles of the spleen, and blood vessels throughout the body. In the final stage, the liver and spleen are enlarged and the kidneys are contracted with severe amyloid deposition (Higuchi et al. 1983) (Fig. 1). 

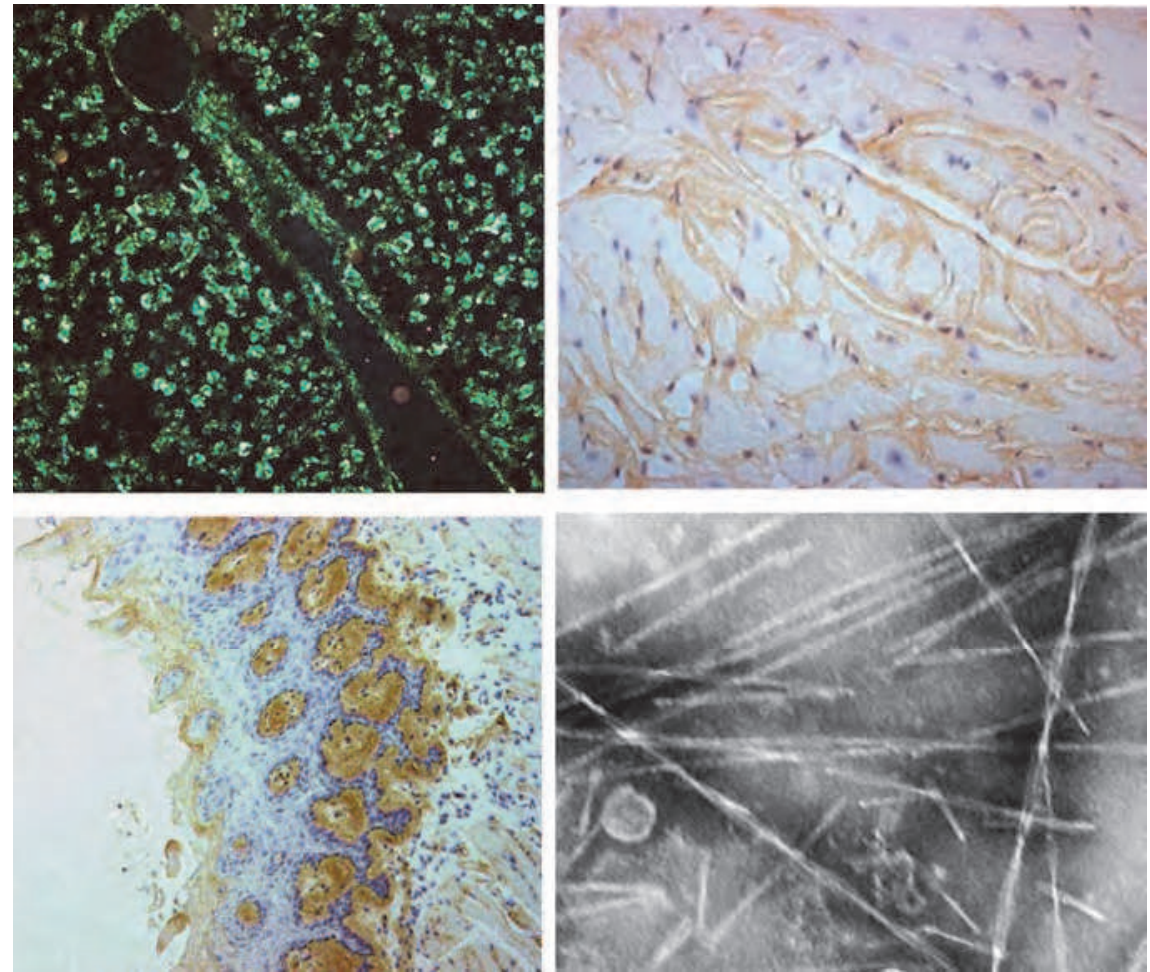

Fig. 1. Mouse systemic senile amyloidosis in SAMP1 mice. AApoAII amyloid fibrils were deposited in the whole body except for the brain parenchyma. Upper-left: heavy amyloid deposition in a liver section strained with Congo red was detected as green birefringence under the polarizing microscope (X100). Upper-right and Lower-left: AApoAII amyloid depositions were determined immunohistochemically in the heart and tongue, respectively (X400). Lower-right; Electron microscopic observation of AApoAII amyloid fibrils isolated from the liver $(\mathrm{X} 50,000)$.

Although senile AApoAII amyloidosis is common in most mouse strains, severe senile amyloidosis has been reported in only a few strains, i.e. SAMP1, SAMP10, SJL/J, LLC, and PS strains. The complete nucleotide sequence of the apoA-II (gene is Apoa2) cDNA was determined in 41 inbred strains of mice (Kunisada et al., 1986; Kitagawa et al., 2003). Among these strains, six alleles containing amino acid substitutions (Apoa2a, Apoa2 ${ }^{b}, A p o a 2^{c}, A p o a 2^{d}$, Apoa2 ${ }^{e}$ and Apoa2f) were identified. Severe amyloid deposition was observed in the strains with the Apoa2c allele (Higuchi et al., 1991). Several genetic analyses indicated that the presence of the Apoa2c allele markedly accelerates age-associated deposition of AApoAII and reduces the lifespan (Naiki et al., 1993; Higuchi et al., 1995; 1996). These results show that type C apoA-II protein in mice is highly amyloidogenic, while SAMR1 and strains with type B apoA-II protein are resistant to the development of amyloidosis. The mice expressing type A apoA-II protein, such as C57BL/6, are moderately amyloidogenic. In vitro amyloid fibril formation (fibril extension) has been reported with the type $\mathrm{C}$ apoA-II protein, but not with the type B apoA-II (Naiki et al., 1992; Fu et al., 2001). Recently we demonstrated that 
the combination of $\mathrm{N}$ - and C-terminal sequences of mouse apoA-II and a conformational change in their secondary structure are essential for polymerization into AApoAII amyloid fibrils (Sawashita et al., 2009). However, the mechanism behind the high amyloidogenicity of type C apoA-II protein in vivo is not yet known.

Congenic R1.P1-Apoa2c mice have the amyloidogenic Apoa2c SAMP1 gene on the genetic background of SAMR1 (Higuchi et al., 1993). Comparable to the donor SAMP1 strain, severe amyloid deposition is present in the R1.P1-Apoa2c strain (Higuchi et al., 1995), and the R1.P1Apoa2c mice are more convenient for use in amyloidosis experiments. A transgenic mouse strain that over-expresses Apoa2c mRNA has been established on the genetic background of R1.P1-Apoa2c. This strain shows higher concentration of apoA-II and greater susceptibility to amyloidosis than the control R1.P1-Apoa2c strain and should prove valuable in future studies of amyloidosis (Ge et al., 2007).

\subsection{Transmission of mouse AApoAll amyloidosis}

Nucleation-dependent polymerization is a postulated model consistent with the kinetics of in vitro amyloid protein fibrillization in amyloidoses such as prion diseases, Alzheimer disease and mouse AApoAII amyloidosis (Jarrett et al., 1993; Harper et al., 1997; Naki et al., 1991). This model is comprised of two phases: 1) nucleation and 2) extension. 1) Nucleus formation requires a series of thermodynamically unfavorable monomer association steps. Thus, the nucleation phase is the rate-limiting step in the development of amyloidosis. 2) Once the nucleus has formed, further addition of monomers becomes thermodynamically favorable, resulting in rapid extension of amyloid fibrils. The dramatically hastened in vitro fibril formation fueled by the addition of amyloid fibrils (nucleus) to a solution of amyloid protein monomers is an example of nucleation-dependent polymerization.

Prion diseases are associated with the accumulation of a pathologic conformational isomer $(\mathrm{PrPSc})$ by a host-derived prion protein $(\mathrm{PrPc})$. Prion transmission or propagation involves the conversion of cellular PrPc into PrPSc via an increase in its $B$-sheet secondary structure content. According to the protein-only hypothesis, introduction of the abnormal conformer $\mathrm{PrPsc}$ into an organism would accelerate the conversion of $\mathrm{PrPc}$ into its pathological conformation (Prusiner et al., 1998; 2006). Thus, the nucleation-dependent polymerization model provides a feasible mechanism for the in vivo conformational conversion of $\mathrm{PrPc}$ to $\mathrm{PrPSc}$ via transmission of prions (Weissmann et al, 1999).

As predicted by the nucleation-dependent polymerization model, in vitro fibril formation experiments in which apoA-II monomers are converted to AApoAII fibrils indicate that the addition of AApoAII amyloid fibrils can facilitate the formation of amyloid fibrils from apoA-II monomers (seeding reaction)(Fig. 2A). Amyloid deposition was notably accelerated after a very small quantity of AApoAII fibrils was administered to R1.P1Apoa2c mice by peripheral injection (intravenous, intraperitoneal or intragastric) or in the diet (Fig. 2B) (Higuchi et al., 1998; Xing et al., 2001). Thus, fibril formation is greatly accelerated in mice through seeding with pre-formed fibrils in vivo in mice (transmission of amyloidosis). The acceleration of amyloidosis fibrils (transmissibility) disappeared completely after treatment with protein denaturing reagents including $6 \mathrm{M}$ guanidine hydrochloride, strong alkaline solution or formic acid. Acceleration was slowed by $6 \mathrm{M}$ urea or by autoclaving, and it was not changed by formalin, DNAse or RNAse treatments. This finding revealed that transmissibility of AApoAII depends on fibril conformation $(\mathrm{H}$. Zhang et al., 2006). 
A

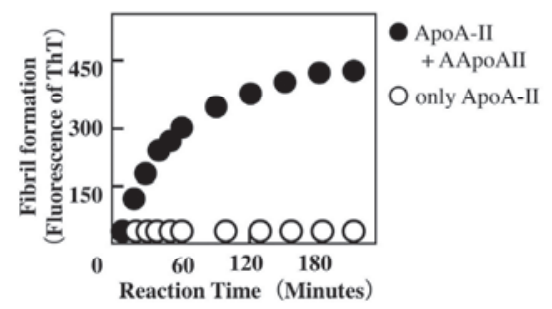

C

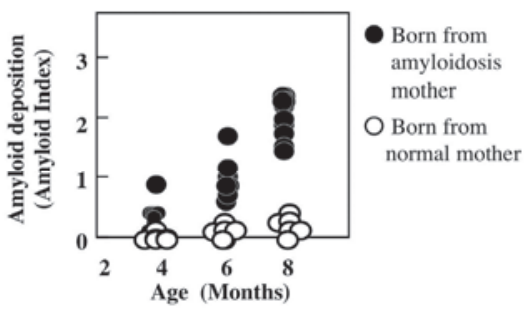

B

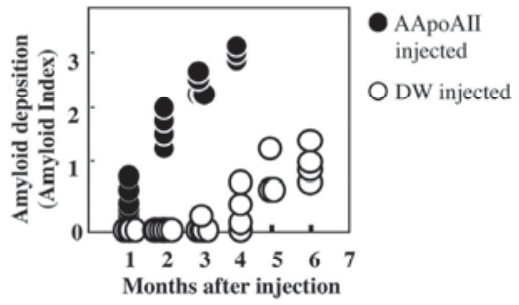

$\mathrm{D}$

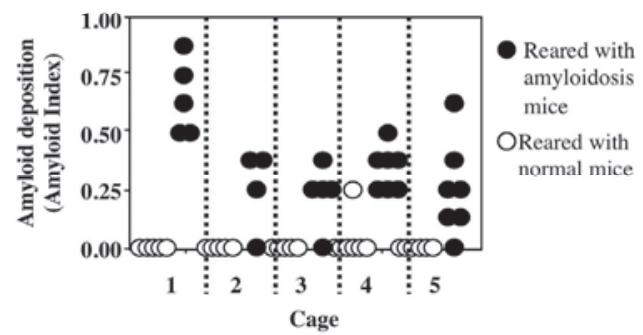

Fig. 2. Transmission of mouse AApoAII amyloidosis in vitro and in vivo. A: Addition of AApoAII amyloid fibrils to a solution of apoA-II monomers accelerates fibril formation in test tubes. B: Injection of AApoAII amyloid fibrils into R1.P1- Apoa2c mice accelerates amyloid deposition. C: Amyloid deposition is accelerated in offspring born to and nursed by mothers with amyloidosis. D: Young R1.P1- Apoa2c mice that were kept in the same cage with mice having amyloidosis for 3 months developed amyloidosis. The intensity of amyloid deposition in mice was determined semi-quantitatively using the amyloid index (AI) as a parameter. The AI parameter represents the average degree of deposition, graded 0 to 4 , in Congo red - stained sections from the seven organs examined (liver, heart, spleen, tongue, stomach, intestine and skin).

Amyloidosis in the offspring of R1.P1- Apoa2c mice was examined to further characterize this transmissibility. Acceleration of amyloidosis was observed in offspring born to, and nursed by, mothers with amyloidosis that was induced by injection of amyloid fibrils 3 months before pregnancy (Fig. 2C) compared with the offspring of control mothers that did not receive injections of amyloid fibrils (Korenaga et al., 2006). Acceleration of amyloidosis was also observed in offspring born to mothers that were not injected, but that were nursed by mothers injected with amyloid fibrils. However, this phenomenon was not observed in offspring born to amyloidosis mothers and nursed by control mothers. Injection of milk obtained from amyloid fibril-injected mothers induced AApoAII amyloidosis in young mice, and amyloid fibrils were detected in the milk of amyloid fibril-injected mothers by electron microscopy. Young mice were reared for 3 months in cages with old R1.P1- Apoa2c mice that had severe amyloid-depositions. All of the young mice developed amyloid deposits (Fig. 1D)(Xing et al., 2001). Amyloid fibrils were detected in feces of mice with amyloidosis. Injection of amyloid fibrils found in feces induced amyloidosis in mice, raising 
the possibility that the oral transmission of amyloid fibrils through feces leads to acceleration of amyloidosis in AApoAII amyloidosis. AApoAII amyloid fibril deposits were found in the skeletal muscles of amyloid-affected mice, primarily in the blood vessels and in the interstitial tissues (endomysium) surrounding muscle fibers (Qian et al., 2010). Amyloid fibril fractions isolated from the muscles could also induce amyloidosis in young mice.

\subsection{Cross-seeding of amyloidosis}

The induction of AApoAII amyloidosis was studied in vivo using various kinds of amyloid fibrils that were isolated from human and mouse tissues or were formed in vitro from synthetic peptides and recombinant proteins. The fibrils were injected intravenously into young R1.P1-Apoa2c mice. At 3 and 6 months after injection, the most severe amyloid depositions were detected in mice injected with mouse AApoAII(C) amyloid fibrils composed of amyloidogenic C type apoA-II, (Fu et al 2004, Yan et al., 2007). Mild amyloid depositions were also detected in tissues of mice that had been injected with other types of fibrils, including synthetic peptides and recombinant proteins. However, no amyloid depositions were found in mice injected with non-amyloid fibril proteins such as serum albumin, transthyretin and mouse apoA-II. This cross-seeding model postulates that there is a direct interaction between newly forming and preexisting heterologous amyloid fibrils in vivo. Thus, induction by various amyloid fibrils supports the prospect of amyloidosis acceleration in animals and humans by heterogeneous amyloid and amyloid-like fibrils in foods or the environment.

AApoAII(C) fibrils were injected intravenously into 2-month-old SAMR1 mice, which carry the less amyloidogenic apoA-II allele $\left(\right.$ Apoa $\left.^{b}\right)$ and develop few, if any, spontaneous amyloid deposits. Ten months after the amyloid injection, deposits were detected on the tongue, and the intensity of deposition increased thereafter, whereas no amyloid was detected in SAMR1 mice injected with distilled water, even after 20 months (Xing et al., 2002). The deposited amyloid fibrils were composed of endogenous type B apoA-II protein, with a different amyloid fibril conformation of the proto-fibril-like figure. Subsequent injection of these AApoAII(B) fibrils induced earlier and more severe amyloidosis in SAMR1 mice than did the first injection of AApoAII(C) fibrils. Thus, adaptation of amyloid fibril structure might happen during deposition in SAMR1 mice. AApoAII(A) fibrils composed of mild amyloidogenic apoA-II allele (Apoa2a) were isolated from the intestine and liver of $\mathrm{C} 57 \mathrm{BL} / 6$ mice. Atomic force microscopy and transmission electron microscopy revealed that the majority of isolated AApoAII(A) fibrils have fine, proto-fibril-like shapes. The AApoAII(A) fibril has a much weaker affinity for thioflavin T than does the AApoAII(C) fibril. The injection of AApoAII(A) fibrils induced amyloid

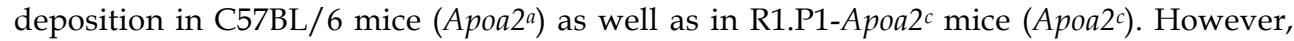

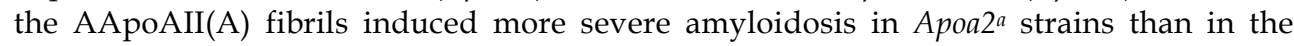
Apoa2c strain (Korenaga et al., 2003).

These findings indicate that AApoAII(A) fibrils isolated from mice having the mildamyloidogenic type A apoA-II, and AApoAII(B) fibrils isolated from mice having the lessamyloidogenic type $\mathrm{B}$ apoA-II, have distinct morphological, pathological and structural characteristics that differ from those of the AApoAII(C) fibrils of amyloidogenic type C apoA-II. Consequently, cross-seeding with the amyloid fibrils induced amyloid deposition in mice that had amyloid protein monomers with different primary structures. 


\section{Transmission of mouse reactive AA amyloidosis}

AA amyloidosis, also known as reactive or secondary amyloidosis, is generally recognized as the predominant form of systemic amyloidosis that occurs in the human and animal kingdoms (Sipe \& Cohen, 2000). The disease is characterized by systemic deposition, primarily in the spleen, liver and, to a lesser extent, in other organs, of extracellular fibrils composed of amyloid A protein. In most species, AA amyloidosis typically occurs secondary to chronic inflammation, infection or neoplasia. SAA protein is an acute phase apolipoprotein reactant primarily produced by hepatocytes under the control of interleukin1, interleukin-6, and tumor necrosis factor- $\alpha$ (Betts et al., 1993; Hagihara et al., 2005). The plasma concentration of SAA is normally very low, but it can increase to $>1,000 \mathrm{mg} /$ liter following an inflammatory stimulus. This protein can be proteolytically processed to produce an N-terminal cleavage product of approximately 44 to 100 residues that is deposited as amyloid in vital organs including the spleen, liver, and kidneys (Kisilevsky et al., 1994). AA amyloidosis occurs in patients with rheumatoid arthritis and other chronic inflammatory diseases. AA can also be induced experimentally in mice by injecting them with silver nitrate, casein, or lipopolysaccharide (LPS), which greatly increases the concentration of circulating SAA (Hoffman \& Benditt, 1982). Intriguing recent data have led to the suggestion that AA amyloidosis might also be transmitted by a prion-like infectious process that involves a seeding-nucleation mechanism, a model that is widely accepted (Lundmark, et al., 2002, 2005; Cui et al., 2002). The lag phase of AA amyloidogenesis can be dramatically shortened by co-injection of "amyloid enhancing factor (AEF)" with an acute inflammatory stimulus. There is evidence that AEF is actually AA fibrils, and that AA amyloidosis might be transmitted by a prion-like mechanism.

\subsection{Transmission of AA amyloidosis in cheetah and cattle}

The cheetah species (Acinonyx jubatus) is in danger of extinction and is included on The World Conservation Union list of vulnerable species. Although efforts have been made in wildlife sanctuary parks and zoos worldwide to prevent extinction, a steady increase in the size of the cheetah population is hampered by the high prevalence of systemic AA amyloidosis, which is regarded as an increasingly important cause of morbidity and mortality in captive cheetahs (Papendick et al 1997). Inflammatory diseases, especially chronic lymphoplasmacytic gastritis, were found in $100 \%$ of cheetahs with AA amyloidosis, and environmental epidemiological studies indicate that breeding conditions have a prominent effect on the incidence of AA amyloidosis. A high rearing density is always associated with early age of onset and with a high incidence and severity of AA amyloidosis. We hypothesize that the propagation of AA amyloidosis among captive cheetah populations may depend on a horizontal transmission pathway (B. Zhang et al., 2008).

Captive cheetahs with severe AA amyloidosis were studied. AA amyloid fibrils were isolated from several tissues and the biochemical and pathological future outcomes of the animals were recorded. In particular, we hypothesized that amyloid fibrils in feces, urine and saliva would be important for the conveyance of amyloid fibrils from the body into the environment and hence for horizontal transmission. We found that cheetah feces contained AA amyloid fibrils that were different from those in the liver, having a smaller molecular weight and a shorter and finer shape. However, we could not find amyloid fibrils in the urine, and unfortunately we could not collect saliva from cheetahs. We 
compared the transmissibility of fecal and liver AA amyloid fibrils using the mouse experimental AA amyloidosis system. Fecal amyloid fibrils had significantly greater transmissibility (Fig. 3A). The infectious activity of fecal AA amyloid fibrils was reduced or abolished by the protein denaturants $6 \mathrm{M}$ guanidine $\mathrm{HCl}$ and formic acid or by AA immunodepletion. With regard to the liver fraction, formic acid treatment caused a nearly complete loss of amyloid-inducing activity, whereas the guanidine-HCl-treated fraction retained high amyloid-inducing activity (Fig. 3B). Thus, we unexpectedly found that the amyloid fibril fraction from feces had smaller amyloid fibrils and higher sensitivity to denaturation treatment than the liver amyloid fibril fraction. In yeast prions, it also has been indicated that $\left[\mathrm{PSI}^{+}\right]$with stronger infectivity typically have less stable fibrils in vivo than strains with weaker infectivity (Krishnan \& Lindquist, 2005), and the prion strain with relatively smaller prion particles is always associated with greater fragility and increased sensitivity to denaturants (Tanaka et al., 2006). Thus, we propose that feces are a potential transmission vehicle that may accelerate AA amyloidosis in captive cheetah populations. These results provide a pathogenic mechanism for AA amyloidosis and suggest possible measures for rescuing cheetahs from extinction.

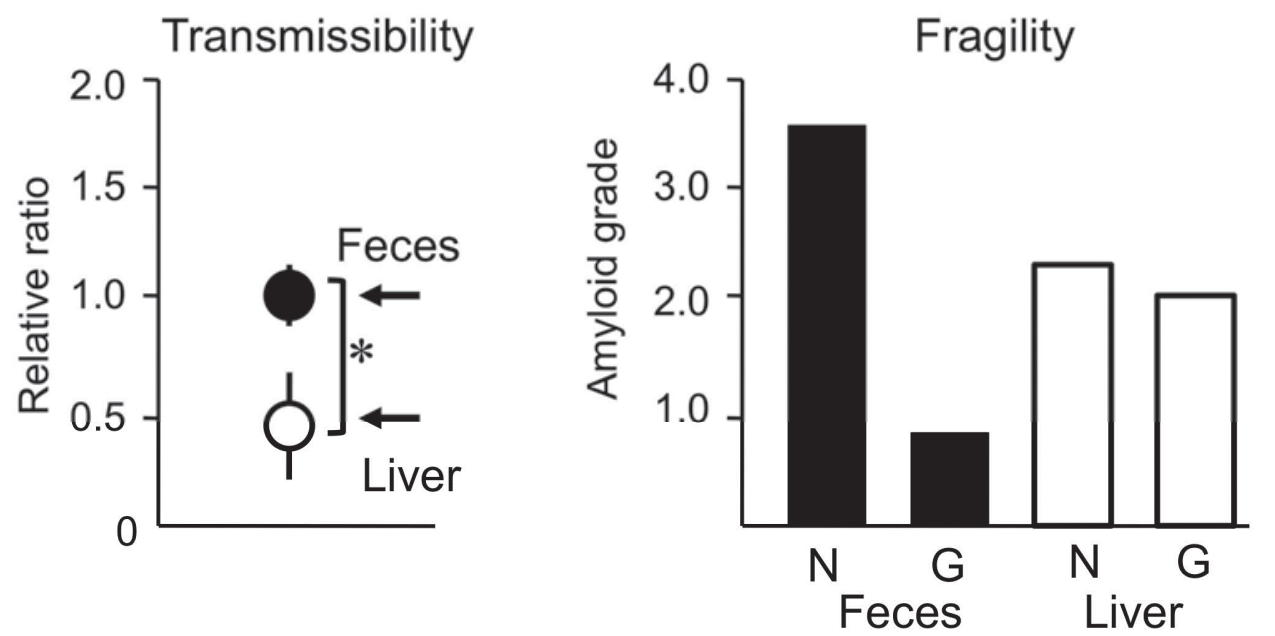

Fig. 3. Transmissibility and fragility of fecal AA amyloid fibrils. A: Quantification of transmissibility of AA amyloid fibrils from feces and liver. The degree of AA deposition in AA-induced mice was determined by isolation of AA amyloid fibril fractions from the spleens of mice in each group (filled circle is fecal; open circle is liver) followed by Western blot analysis and quantification using an image analyzer. The means and SE were determined by the relative ratios of AA amyloid protein levels versus the group receiving $10 \mu \mathrm{g}$ of amyloid fibrils fraction from the feces $\left({ }^{*}, \mathrm{P}<0.05\right)$. B: Fecal and liver AA amyloid fibril fractions were untreated $(N)$, or treated with guanidine-hydrochloride $(G)$ or formic acid (F) and injected into mice to induce AA amyloidosis. Equal quantities of amyloid fractions $(100 \mu \mathrm{g})$ were used in each experiment. The degree of amyloidosis was determined by the amyloid deposition observed in Congo red-stained sections of the spleen. 


\section{Analysis of transmission in mouse models of another systemic amyloidosis}

Patients on long-term hemodialysis can develop dialysis-related amyloidosis (DRA) due to deposition of $\beta_{2}$-microglobulin $\left(\beta_{2} \mathrm{~m}\right)$ into amyloid fibrils $\left(A \beta_{2} M\right)$ (Gejyo et al., 1985). Despite intensive biochemical studies, the pathogenesis of amyloid deposition in DRA patients remains poorly understood. Intact wild type $\beta_{2} \mathrm{~m}$ is unable to form amyloid fibrils under physiological conditions in test tubes. However, the addition of $\mathrm{AB}_{2} \mathrm{M}$ amyloid fibrils induces fibril formation following a nucleation dependent polymerisation model (Yamaguchi et al., 2001; Xue et al., 2008). To elucidate the mechanisms that underlie $\mathrm{A}_{2} \mathrm{M}$ fibril formation in DRA, transgenic mice were generated that overexpress human $\aleph_{2} \mathrm{~m}$ protein on a mouse $\mathrm{B} 2 \mathrm{~m}$ gene knockout background (hB2 $\mathrm{MTg}^{+/+} \mathrm{mB} 2 \mathrm{~m} \mathrm{-/-}$ ), and the possibility of transmission was examined using these model mice ( $\mathrm{P}$. Zhang et al., 2009).

Families with a variant transthyretins (TTR V30M)-associated familial amyloidotic polyneuropathy (FAP) exhibit genetic anticipation, with TTR V30M-amyloid depositing noted at an earlier age in successive generations (Yamamoto et al., 1998). The molecular basis of anticipation in FAP remains to be determined. The possibility that ATTR amyloid fibrils might be excreted in the milk of the FAP patients was suggested (Tokuda et al., 2007). We asked if administration of TTR-amyloid fibrils (ATTR) extracted from the heart of an FAP TTR V30M patient would accelerate ATTR deposition in transgenic mice expressing the human mutant TTR gene responsible for FAP TTR V30M (Wei et al., 2004).

\subsection{Analysis of the transmission of $A B_{2} M$ amyloidosis in human $B_{2} m$ transgenic mice}

Transgenic mice that overexpress human $\mathrm{B} 2 \mathrm{~m}$ protein were generated on a mouse $\mathrm{B} 2 \mathrm{~m}$ gene knockout background (hB2MTg $\left.{ }^{+/+}, \mathrm{mB} 2 \mathrm{~m}^{-/-}\right)$. First, the pCAGGS-hB2M vector was created, and a human $132 \mathrm{~m}$ gene $(\mathrm{hB} 2 \mathrm{M})$ cDNA fragment was isolated by reverse transcription-PCR (RT-PCR) of messenger RNA extracted from human liver and cloned into pCAGGS. The hB2M cDNA was expressed under the control of the cytomegalovirus immediate early gene enhancer (CMV-IE)/chicken $B$-actin promoter and rabbit B-globin poly(A) signal (Fig. 4). The hB2M transgene copy number was determined by real-time PCR and calculated as 10 for homozygous hB2MTg ${ }^{+/}$. To exclude possible effects of endogenous mouse $12 \mathrm{~m}$, transgenic mice were crossed with mouse $132 \mathrm{~m}(\mathrm{mB} 2 \mathrm{~m})$ knockout mice. The $\mathrm{hB} 2 \mathrm{MTg}^{+/+}, \mathrm{mB} 2 \mathrm{~m}^{-/-}$mice express a high level of human $\mathrm{B} 2 \mathrm{~m}$ protein in many tissues and also have a high plasma $12 \mathrm{~m}$ concentration $(192.8 \mathrm{mg} / \mathrm{L})$. This concentration is $>100$ times higher than that observed in healthy humans and $>4$ times higher than that detected in patients on dialysis. These mice were checked for spontaneous amyloidosis, but amyloid deposition of $132 \mathrm{~m}$ protein was not observed in aged ( 2 years) mice. Next we attempted to accelerate amyloidosis by injecting human $\mathrm{A} ß 2 \mathrm{M}$ amyloid fibrils isolated from the amyloid-laden ligaments of the patient, and artificial amyloid fibrils were produced from recombinant human $\$ 2 \mathrm{~m}$ protein. Amyloid deposition of $\mathrm{B} 2 \mathrm{~m}$ protein was not observed in animals injected with amyloid fibrils. However, mouse senile AApoAII amyloidosis was detected, particularly in the joints of mice that were injected with amyloid fibrils. 


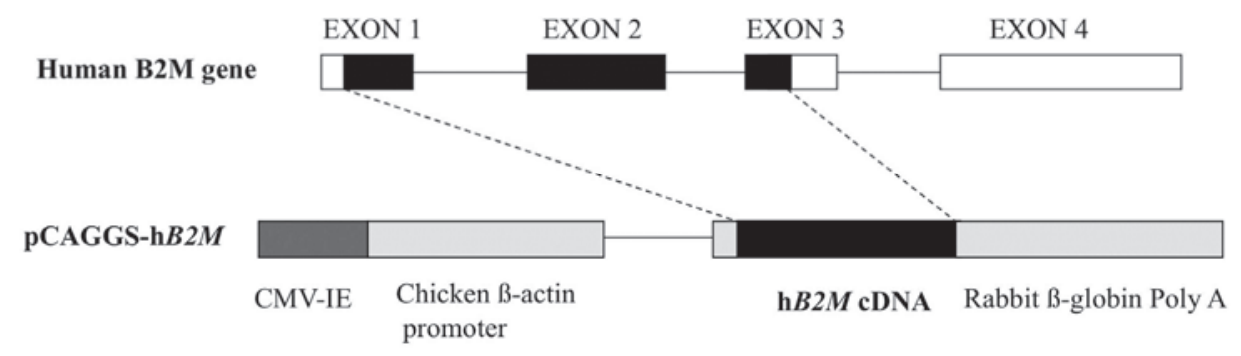

Fig. 4. Establishment of hB2M transgenic mice. The pCAGGS-hB2M targeting vector containing the human $\AA_{2}$ m cDNA inserted between the CMV-IE enhancer/chicken $B$-actin promoter and the rabbit $B$-globin poly(A) site.

This study demonstrates that this mouse model could be valuable in studying the components and conditions that promote DRA, and the results indicate that neither high plasma concentrations of $\mathrm{h} \aleph_{2} \mathrm{~m}$ nor seeding with pre-existing amyloid fibrils may be sufficient to induce $A \beta_{2} \mathrm{M}$. We attempted to enhance amyloidosis by inducing arthritis through injection of the following substances: a monoclonal antibody against type II collagens, LPS (which induces inflammatory reactions), type I collagen and heparin solution, all of which are known to induce amyloid fibril formation in the test tube (Relini et al., 2006; Bellotti \& Chiti, 2008). However, we have not been able to induce $A \Omega_{2} \mathrm{M}$ amyloid deposition in mice.

\subsection{Analysis of the transmission of TTR amyloidosis in human variant TTR transgenic mice}

Transgenic mice producing human variant TTR due to a mutant TTR (V30M) gene with its endogenous $6.0 \mathrm{~kb}$ upstream region were generated by Maeda et al (Kohno et al., 1997). The variant TTR transgene copy number was determined to be $\sim 60$ for homozygous hTTR$V 30 \mathrm{MTg}^{+/+}$. To exclude possible effects of endogenous mouse Ttr, transgenic mice were crossed with $\mathrm{Ttr}$ knockout mice. The Ttr $\%$, hTTR-V30MTg ${ }^{+/ ?}$ mice expressing a high level of human variant TTR protein, which was produced mainly in the liver, were used (Fig. 5).

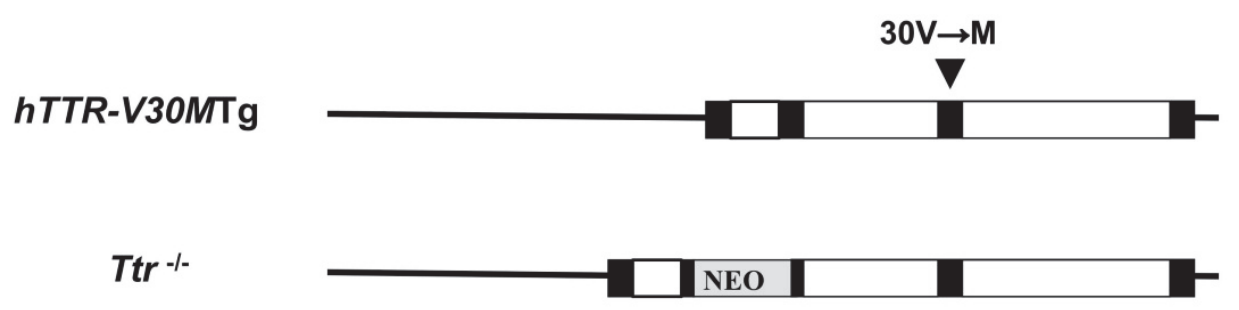

Fig. 5. Establishment of Ttr $/$, hTTR-V30MTg ${ }^{+/ ?}$ mice. Variant human Ttr transgenic mice were crossed with mouse Ttr knockout mice.

We asked if administration of TTR-amyloid fibrils (ATTR) extracted from the heart of an FAP TTR V30M patient would accelerate ATTR deposition in these transgenic mice. Although the administration of amyloid fibrils did accelerate deposition of AApoAII fibrils 
in several organs including intestine, esophagus, heart kidney, liver and so on by a crossseeding effect, deposition of ATTR was not observed. Thus, these experiments present, for the first time, evidence that the degree of ATTR inducibility is low relative to that of AApoAII. This leads us to suggest that administration of ATTR may not explain the genetic anticipation that occurs in FAP.

\section{Discussion and conclusion}

The amyloidogenic SAMP1, congenic R1.P1-ApoA2c and transgenic $\mathrm{mApoA2}{ }^{c} \mathrm{Tg}$ strains did not experience spontaneous amyloid deposition when they were reared in specific pathogen free (SPF) and amyloidosis-free conditions. This finding suggested that environmental conditions affect amyloidosis and that pre-existing amyloid fibrils make a significant contribution to the transmission or induction of AApoAII amyloidosis in vivo. (Higuchi et al., unpublished data). Moreover, cross-seeding between heterogeneous amyloid fibrils or fibril-like structures and amyloidogenic proteins has been reported in vitro and in vivo in both mouse AApoAII and AA amyloidosis (Fu et al., 2004; P. Westermark et al., 2009). Thus, the possibility of acceleration and induction of amyloidosis in animals and humans by heterogeneous amyloid fibrils in foods or the environment should be considered (Fig.6).

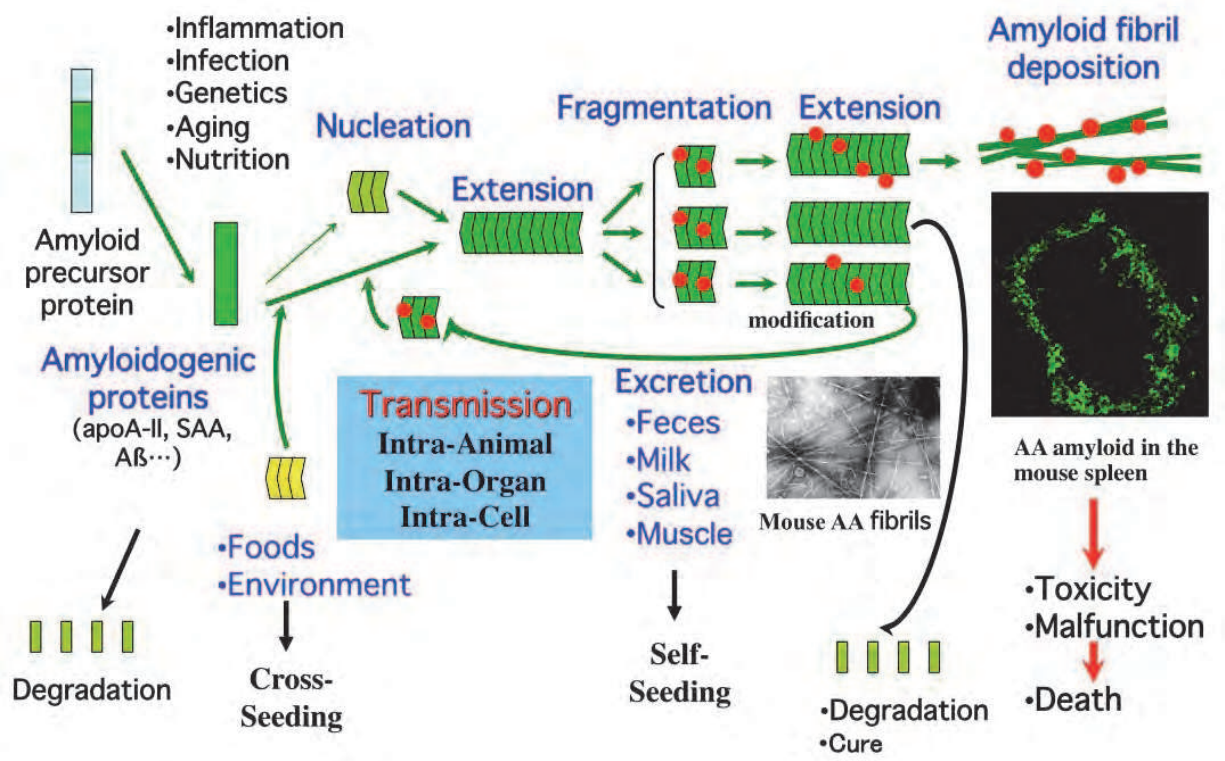

Fig. 6. Transmission mechanism in systemic AApoAII and AA amyloidosis. HDLassociated ApoA-II and SAA circulate in the blood. Spontaneous formation of the nucleus is slow and rare. Homologous or heterologous amyloid fibrils act as seeds and facilitate the formation of amyloid fibrils (self and cross-seeding). Extended amyloid fibrils were fragmented to make new seeds. Fibril associated molecules that stabilize or modify the amyloid fibril structure. Amyloid fibrils are excreted from the body into feces, milk, saliva and muscle, and other animals may then take these into their bodies. Transmission should be observed at 3 levels; intra-animal, intra-organ and intra cells. 
Recently, researchers have recognized that misfolded proteins play important roles in many neuro- degenerative diseases, including Alzheimer's disease (Eisele et al., 2010), Parkinson's disease (Hansen et al., 2011), Huntington's disease (Ren et al., 2009), tauopathies (Clavaguera et al 2009) and so on. These disorders resemble classic prion diseases, as the disease can be spread by imparting the pathological structure of the proteins to new and normal cellular counterparts, and these seeds can recruit endogenous proteins (Angot et al., 2010). Although none of these mis-folded proteins behave like typical infectious agents, the possible exception is systemic AApoAII and AA amyloidosis (Walker et al., 2006; G.T. Westermark \& P. Westermark, 2010). Inter-individual infectivity of these two amyloidoses has been revealed experimentally and clinical outcomes are similar to those of the prion diseases. However, a paucity of epidemiological evidence argues against the role that transmission of amyloidosis may play in the human amyloidosis. How do the pathologic agents (amyloid fibrils) penetrate the recipient body? How do they spread throughout the body? Our studies have revealed that feces, milk, saliva and muscle are possible transporters through nasal and gastric pathways for interanimal transmission. In particular, the amyloid fibrils in feces are noteworthy, since these fibrils showed higher fragility and transmissibility. Unstable species of infections prion (PrPSc) and yeast prion (Sup35) fibrils, which readily break and generate further free ends that can then act as seeds, have been reported to be important for transmission (Tanaka et al., 2006; Wille et al., 2009).

Analysis of amyloid fibril formation of $\beta_{2} \mathrm{~m}$ protein in test tubes revealed clearly the acceleration of fibril extension in the presence of pre-existing amyloid fibrils. However, injection of $A \aleph_{2} \mathrm{M}$ fibrils did not induce amyloidosis in transgenic mice having a high blood concentration of human $\beta_{2} \mathrm{~m}$. Thus, transmission seems to not contribute to the development of systemic $\mathrm{AB}_{2} \mathrm{M}$ amyloidosis associated with long-term dialysis. However, the connections between in vitro studies performed in extreme and simplified conditions and in vivo observations in more complex organisms are important, and we need to improve and extend future experiments using model systems in order to understand the pathogenesis of human diseases.

The concept of transmission via self-propagating structures of proteins or by seeding is unique, and it is important to understand the pathogenesis of protein mis-folding diseases. The animal models of systemic amyloidosis described here should prove valuable in further studies of the pathogenesis, genetics, therapeutics and transmission of amyloidosis.

\section{Acknowledgments}

We thank Drs. Matsumoto K and Tomozawa H, Ms. Nishio A and Suzuki K, Mr. Kamatani K. (Research Support Center for Human and Environmental Sciences, Shinshu University) for animal care and technical assistance. This work was supported by the Ministry of Education, Culture, Sports, Science and Technology of Japan, Grants-in-Aid for Scientific Research (B) 20300144 and Science Research on Priority Areas 22020015, and by grants from the Intractable Disease Division, the Ministry of Health, Labor and Welfare to Research Committees for Amyloidosis.

\section{References}

Aguzzi, A. (2009) Beyond the prion principle. Nature, Vol. 459(7249): 924-925. 
Bellotti, V. \& Chiti F. (2008) Amyloidogenesis in its biological environment: challenging a fundamental issue in protein misfolding diseases. Curr Opin Struct Biol, Vol. 18 (6): 771-779.

Benson, MD., James, S., Scott, K., Liepnieks, JJ. \& Kluve-Beckerman, B. (2008). Leukocyte chemotactic factor 2: A novel renal amyloid protein. Kidney Int, Vol.74(2): 218-222.

Betts, JC., Cheshire, JK, Akira, S., Kishimoto, T. \& Woo, P. (1993) The role of NF-kappa B and NF-IL6 transactivating factors in the synergistic activation of human serum amyloid A gene expression by interleukin-1 and interleukin-6. J. Biol. Chem, Vol. 268 (34): 25624-25631.

Brundin, P., Melki, R., \& Kopito, R. (2010) Prion-like transmission of protein aggregates in neurodegenerative diseases. Nat Rev Mol Cell Biol. Vol 11(4): 301-307.

Clavaguera, F., Bolmont, T., Crowther, RA., Abramowski, D., Frank, S., Probst, A., Fraser, G., Stalder, AK., Beibel, M., Staufenbiel, M., Jucker, M., Goedert, M. \& Tolnay, M. (2009) Transmission and spreading of tauopathy in transgenic mouse brain. Nat Cell Biol. Vol. 11(7): 909-913.

Cui, D., Kawano, H., Takahashi, M., Hoshii, Y., Setoguchi, M., Gondo. T. \& Ishihara, T. (2002) Acceleration of murine AA amyloidosis by oral administration of amyloid fibrils extracted from different species. Pathol. Int, Vol. 52(4): 264-270.

Eisele, YS., Obermüller, U., Heilbronner, G., Baumann, F., Kaeser, SA., Wolburg, H., Walker, LC., Staufenbiel, M., Heikenwalder, M. \& Jucker, M. (2010) Peripherally applied Abeta-containing inoculates induce cerebral beta-amyloidosis. Science, Vol. 330(6006): 980-982.

Fu, L., Matsuyama, I., Chiba, T., Xing, Y., Korenaga T, Guo Z, Fu X, Nakayama J, Mori M, \& Higuchi K. (2001) Extrahepatic expression of apolipoprotein A-II in mouse tissues: possible contribution to mouse senile amyloidosis. J Histochem Cytochem, Vol. 49(6): 739-748.

Fu, X., Korenaga, T., Fu, L., Xing, Y., Guo, Z., Matsushita, T., Hosokawa, M., Naiki, H., Baba S., Kawata, Y., Ikeda, S., Ishihara, T., Mori, M. \& Higuchi K. (2004) Induction of AApoAII amyloidosis by various heterogeneous amyloid fibrils. FEBS Lett, Vol. 563(1-3): 179-184.

Ge, F., Yao, J., Fu, X., Guo, Z., Yan, J., Zhang, B., Zhang, H., Tomozawa, H., Miyazaki, J., Sawashita, J., Mori, M. \& Higuchi, K. (2007) Amyloidosis in transgenic mice expressing murine amyloidogenic apolipoprotein A-II (Apoa2c). Lab Invest, Vol. 87(7): 633-643.

Gejyo, F., Yamada, T., Odani, S., Nakagawa, Y., Arakawa, M., Kunitomo, T., Kataoka, H., Suzuki, M., Hirasawa, Y., Shirahama, T., et al. (1985) A new form of amyloid protein associated with chronic hemodialysis was identified as b2-microglobulin. Biochem Biophys Res Commun, Vol. 129(3): 701-706.

Hagihara, K., Nishikawa, T., Sugamata, Y., Song, J., Isobe, T., Taga, T. \& Yoshizaki, K. (2005) Essential role of STAT3 in cytokine-driven NF-kappaB-mediated serum amyloid A gene expression. Genes Cells. Vol.10 (11): 1051-1063.

Hansen, C., Angot, E., Bergström, AL., Steiner, JA., Pieri, L., Paul, G., Outeiro, TF., Melki, R., Kallunki, P., Fog, K., Li, JY. \& Brundin, P. (2011) $\alpha$-Synuclein propagates from 
mouse brain to grafted dopaminergic neurons and seeds aggregation in cultured human cells. J Clin Invest. Vol. 121(2): 715-725.

Harper, JD., \& Lansbury, PT Jr. (1997) Models of amyloid seeding in Alzheimer's disease and scrapie: mechanistic truths and physiological consequences of the timedependent solubility of amyloid proteins. Annu Rev Biochem, Vol. 66: 385-407.

Higuchi, K., Matsumura, A., Hashimoto, K., Honma, A., Takeshita, S., Hosokawa, M., Yasuhira, K. \& Takeda, T. (1983) Isolation and characterization of senile amyloid-related antigenic substance (SASSAM) from mouse serum. Apo SASSAM is a low molecular weight apoprotein of high density lipoprotein. J Exp Med, Vol. 158((5): 1600-1614.

Higuchi, K., Matsumura, A., Honma, A., Takeshita, S., Hashimoto, K., Hosokawa, M., Yasuhira., K. \& Takeda, T. (1983) Systemic senile amyloid in senescence-accelerated mice. A unique fibril protein demonstrated in tissues from various organs by the unlabeled immunoperoxidase method. Lab Invest, Vol. 48(2): 231-240.

Higuchi, K,. Yonezu, T., Kogishi, K., Matsumura, A., Takeshita, S., Higuchi, K., Kohno, A., Matsushita, M., Hosokawa, M. \& Takeda, T. (1986) Purification and characterization of a senile amyloid-related antigenic substance (apoSASSAM)

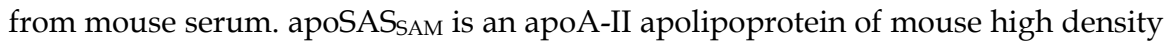
lipoprotein J Biol Chem, Vol. 261(27): 12834-12840.

Higuchi, K., Kitagawa, K., Naiki, H., Hanada, K., Hosokawa, M. \& Takeda T. (1991) Polymorphism of apolipoprotein A-II (apoA-II) among inbred strains of mice. Relationship between the molecular type of apoA-II and mouse senile amyloidosis. Biochem J, 279 (2): 427-433.

Higuchi, K., Kitado, H., Kitagawa, K., Kogishi, K., Naiki, H. \& Takeda T. (1993) Development of congenic strains of mice carrying amyloidogenic apolipoprotein A-II $($ Apoa 2 c). Apoa2c reduces the plasma level and the size of high density lipoprotein. FEBS Lett, Vol. 317(3): 207-210.

Higuchi, K., Naiki, H., Kitagawa, K., Kitado H, Kogishi K, Matsushita T. \& Takeda T. (1995) Apolipoprotein A-II gene and development of amyloidosis and senescence in a congenic strain of mice carrying amyloidogenic ApoA-II. Lab Invest, Vol. 72(1): 7582.

Higuchi, K., Wang, J., Kitagawa, K., Matsushita, T., Kogishi, K., Naiki, H., Kitado, H., \& Hosokawa, M. (1996) Accelerated senile amyloidosis induced by amyloidogenic ApoA-II gene shortens the life span of mice but does not accelerate the rate of senescence. J Gerontol A Biol Sci Med Sci, Vol. 51(4): B295-B302.

Higuchi, K., Kogishi, K., Wang, J., Chen, X., Chiba, T., Matsushita, T., Hoshii, Y., Kawano, H., Ishihara, T., Yokota, T. \& Hosokawa M. (1998) Fibrilization in mouse senile amyloidosis is fibril conformation-dependent. Lab. Invest. Vol.78(12): 1535-1542.

Higuchi, K., Hosokawa, M. \& Takeda, T. (1999) Senescence-accelerated mouse. Methods Enzymol. Vol. 309: 674-686.

Hoffman, J.S, \& Benditt, EP. (1982) Changes in high density lipoprotein content following endotoxin administration in the mouse. Formation of serum amyloid protein-rich subfractions. J Biol Chem, Vol. 257(17): 10510-10517. 
Jarrett, JT. \& Lansbury, PT Jr. (1993) Seeding "one-dimensional crystallization" of amyloid: a pathogenic mechanism in Alzheimer's disease and scrapie? Cell. Vol. 73(6): 10551058.

Kisilevsky, R., Narindrasorasak, S., Tape, C., Tan, R., \& Boudreau, L. (1994) During AA amyloidogenesis is proteolytic attack on serum amyloid A a pre- or postfibrillogenic event? Amyloid, Vol. 1(3), 174-183.

Kitagawa, K., Wang, J., Mastushita, T., Kogishi, K., Hosokawa, M., Fu, X., Guo, Z., Mori, M. \& Higuchi K. (2003) Polymorphisms of mouse apolipoprotein A-II: seven alleles found among 41 inbred strains of mice. Amyloid, Vol. 10(4): 207-214.

Kohno, K., Palha, JA., Miyakawa, K., Saraiva, MJ., Ito, S., Mabuchi, T., Blaner, WS., Iijima, H., Tsukahara, S., Episkopou, V., Gottesman, ME., Shimada, K., Takahashi, K., Yamamura, K. \& Maeda S. (1997) Analysis of amyloid deposition in a transgenic mouse model of homozygous familial amyloidotic polyneuropathy. Am J Pathol. Vol. 150(4): 1497-508.

Korenaga, T., Fu, X., Xing, Y., Matsusita, T., Kuramoto, K., Syumiya, S., Hasegawa, Z., Naiki, H., Ueno, M., Ishihara, T., Hosokawa, M., Mori, M. \& Higuchi K. (2004) Tissue distribution, biochemical properties, and transmission of mouse type A AApoAII amyloid fibrils. Am. J. Pathol, Vol. 164(5): 1597-19606.

Korenaga, T., Yan, J., Sawashita, J., Matsushita, T., Naiki, H., Hosokawa, M., Mori, M., Higuchi, K. \& Fu X. (2006) Transmission of amyloidosis in offspring of mice with AApoAII amyloidosis. Am J Pathol, Vol. 168(3): 898-906.

Krishnan, R. \& Lindquist, SL (2005) Structural insights into a yeast prion illuminate nucleation and strain diversity. Nature Vol. 435 435(7043): 765-772

Kunisada, T., Higuchi, K., Aota, S., Takeda, T. \& Yamagishi, H. (1986) Molecular cloning and nucleotide sequence of cDNA for murine senile amyloid protein: nucleotide substitutions found in apolipoprotein A-II cDNA of senescence accelerated mouse (SAM). Nucleic Acids Res, Vol. 14(14): 5729-5740.

Lundmark, K., Westermark, GT., Nystrom, S., Murphy, CL., Solomon, A. \& Westermark P. (2002) Transmissibility of systemic amyloidosis by a prion-like mechanism.Proc. Natl. Acad. Sci. U S A., Vol. 99(10): 6979-6984. Erratum. 2003, Proc. Natl. Acad. Sci. U $S$ A. Vol. 100(6), 3543.

Lundmark, K., Westermark, GT, Olsén A. \& Westermark, P. (2005) Protein fibrils in nature can enhance amyloid protein A amyloidosis in mice: Cross-seeding as a disease mechanism. Proc Natl Acad Sci U S A. Vol. 102(17): 6098-6102.

Naiki, H., Higuchi, K., Nakakuki, K. \& Takeda, T. (1991) Kinetic analysis of amyloid fibril polymerization in vitro. Lab Invest, Vol. 65(1): 104-110. Erratum in: Lab Invest, 67(5): 652.

Naiki, H., Higuchi, K., Shimada, A., Takeda, T. \& Nakakuki, K. (1993) Genetic analysis of murine senile amyloidosis. Lab Invest, Vol. 68(3): 332-337.

Papendick, RE., Munson, L., O’Brien, TD. \& Johnson, KH (1997) Systemic AA amyloidosis in captive cheetahs (Acinonyx jubatus). Vet Pathol, Vol. 34(6): 549-556.

Prusiner, SB., Scott, MR., DeArmond, SJ. \& Cohen, FE. (1998) Prion protein biology. Cell, Vol. 93(3): 337-348. 
Prusiner, SB. \& McCarty, M. (2006) Discovering DNA encodes heredity and prions are infectious proteins. Annu Rev Genet, Vol. 40: 25-45.

Qian, J., Yan, J., Ge, F., Zhang, B., Fu, X., Tomozawa, H., Sawashita, J., Mori, M. \& Higuchi, K. (2010) Mouse senile amyloid fibrils deposited in skeletal muscle exhibit amyloidosis-enhancing activity. PLoS Pathog. Vol. 6(5): e1000914.

Ren, PH., Lauckner, JE., Kachirskaia, I., Heuser, JE., Melki, R. \& Kopito, RR. (2009) Cytoplasmic penetration and persistent infection of mammalian cells by polyglutamine aggregates. Nat Cell Biol, Vol. 11(2): 219-225.

Sawashita, J., Kametani, F., Hasegawa, K., Tsutsumi-Yasuhara S, Zhang B, Yan J, Mori M, Naiki H. \& Higuchi K. (2009). Amyloid fibrils formed by selective N-, C-terminal sequences of mouse apolipoprotein A-II. Biochim Biophys Acta; Vol. 1794(10): 15171529.

Sipe, JD. \& Cohen, AS. (2000) Review: history of the amyloid fibril.J Struct Biol. Vol. 130(2-3): 88-89.

Sipe, JD.; Benson, MD., Buxbaum, JN., Ikeda, S., Merlini, G., Saraiva, MJ. \& Westermark, P. (2010). Amyloid fibril protein nomenclature: 2010 recommendations from the nomenclature committee of the International Society of Amyloidosis. Amyloid. Vol.17 (3-4), 101-104.

Takeda, T., Hosokawa, M., Takeshita, S., Irino, M., Higuchi, K., Matsushita, T., Tomita, Y., Yasuhira, K., Hamamoto, H., Shimizu, K., Ishii, M. \& Yamamuro, T. (1981) A new murine model of accelerated senescence. Mech. Ageing Dev., Vol 17(2): 183-194.

Takeshita, S., Hosokawa, M., Irino, M., Higuchi, K., Shimizu, K., Yasuhira, K. \& Takeda, T. (1982) Spontaneous age-associated amyloidosis in senescence-accelerated mouse (SAM). Mech Ageing Dev, Vol. 20(1): 13-23.

Tanaka, M., Collins, SR., Toyama, BH. \& Weissman, JS. (2006) The physical basis of how prion conformations determine strain phenotypes. Nature Vol. 442 (7102): 585589.

Tojo, K., Tokuda, T., Hoshii, Y., Fu, X., Higuchi, K., Matsui, T., Kametani, F., \& Ikeda S. Unexpectedly high incidence of visceral AA-amyloidosis in slaughtered cattle in Japan. Amyloid. 12(2): 103-108.

Tokuda, T., Takei, Y., Takayama, B., Hoshii, Y. \& Ikeda S. (2007) Severe amyloid deposition in mammary glands of familial amyloid polyneuropathy patients. Amyloid. Vol. 14(3): 249-253.

Walker, LC., Levine, H3rd., Mattson, MP. \& Jucker, M. (2006) Inducible proteopathies. Trends Neurosci, Vol. 29(8): 438-443.

Wei, L., Kawano, H., Fu, X., Cui, D., Ito, S., Yamamura, K., Ishihara, T., Tokuda, T., Higuchi, K. \& Maeda S. (2004) Deposition of transthyretin amyloid is not accelerated by the same amyloid in vivo. Amyloid. Vol. 11(2): 113-120.

Weissmann, C. (1999) Molecular genetics of transmissible spongiform encephalopathies. J Biol Chem, Vol. 274(1): 3-6.

Westermark, GT. \& Westermark P. (2010) Prion-like aggregates: infectious agents in human disease. Trends Mol Med. Vol. 16(11): 501-507. 
Westermark, P., Lundmark, K. \& Westermark GT. (2009) Fibrils from designed nonamyloid-related synthetic peptides induce AA-amyloidosis during inflammation in an animal model. PLoS One. Vol. 4(6): e6041.

Wille, H., Bian, W., McDonald, M., Kendall, A., Colby, DW., Bloch, L., Ollesch, J., Borovinskiy, AL., Cohen, FE., Prusiner, SB. \& Stubbs, G. (2009) Natural and synthetic prion structure from X-ray fiber diffraction. Proc Natl Acad Sci U S A. Vol. 106(40): 16990-16995.

Xing, Y., Nakamura, A., Chiba, T., Kogishi, K., Matsushita, T., Li, F., Guo, Z., Hosokawa, M., Mori, M. \& Higuchi K. (2001) Transmission of mouse senile amyloidosis. Lab Invest. Vol. 81(4): 493-499.

Xing, Y., Nakamura, A., Korenaga, T., Guo, Z., Yao, J., Fu, X., Matsushita, T., Kogishi, K., Hosokawa, M., Kametani, F., Mori, M. \& Higuchi, K. (2002), Induction of protein conformational change in mouse senile amyloidosis. J Biol Chem, 277(36): 3316433169.

Xue, WF., Homans, SW. \& Radford, SE. (2008) Systematic analysis of nucleation-dependent polymerization reveals new insights into the mechanism of amyloid self-assembly. Proc Natl Acad Sci U S A, Vol. 105(26): 8926-8931

Yamada, M., Kotani, Y., Nakamura, K., Kobayashi, Y., Horiuchi, N., Doi, T., Suzuki, S., Sato, N., Kanno, T. \& Matsui T. (2006) Immunohistochemical distribution of amyloid deposits in 25 cows diagnosed with systemic AA amyloidosis. J Vet Med Sci. 68(7): 725-729.

Yamaguchi, I., Hasegawa, K., Naiki, H., Mitsu, T., Matuo, Y. \& Gejyo, F. (2001) Extension of $\mathrm{A}_{2} \mathrm{M}$ amyloid fibrils with recombinant human $\aleph_{2}$-microglobulin. Amyloid Vol. 8(1): 30-40.

Yamamoto, K., Ikeda, S., Hanyu, N., Takeda, S. \& Yanagisawa, N. (1998) A pedigree analysis with minimised ascertainment bias shows anticipation in Met30transthyretin related familial amyloid polyneuropathy. J Med Genet. Vol.35(1): 23-30.

Yan, J., Fu, X., Ge F., Zhang, B, Yao, J., Zhang, H., Qian, J., Tomozawa, H., Naiki, H., Sawashita, J., Mori, M. \& Higuchi K. (2007) Cross-seeding and cross-competition in mouse apolipoprotein A-II amyloid fibrils and protein A amyloid fibrils. Am J Pathol. 171(1): 172-1780.

Yonezu, T., Higuchi, K., Tsunasawa, S., Takagi, S., Sakiyama, F. \& Takeda, T. (1986) High homology is present in the primary structures between murine senile amyloid protein (ASSAM) and human apolipoprotein A-II. FEBS Lett, Vol. 203(2): 149-152.

Yoshida, T., Zhang, P., Fu, X., Higuchi, K. \& Ikeda S. (2009) Slaughtered aged cattle might be one dietary source exhibiting amyloid enhancing factor activity. Amyloid. 16(1): 2531.

Zhang, B., Une, Y., Fu, X., Yan, J., Ge, F., Yao, J., Sawashita, J., Mori, M., Tomozawa, H., Kametani, F. \& Higuchi, K. (2008) Fecal transmission of AA amyloidosis in the cheetah contributes to high incidence of disease. Proc Natl Acad Sci U S A. Vol. 105(20): 7263-7268. 
Zhang, H., Sawashita, J., Fu, X., Korenaga, T., Yan, J., Mori, M., \& Higuchi. K. (2006) Transmissibility of mouse AApoAII amyloid fibrils: inactivation by physical and chemical methods. FASEB J Vol. 20(7): 1012-1014.

Zhang, P., Fu, X., Sawashita, J., Yao, J., Zhang, B., Qian, J., Tomozawa, H., Mori, M., Ando, Y., Naiki, H. \& Higuchi K. (2010) Mouse model to study human Aß2M amyloidosis: generation of a transgenic mouse with excessive expression of human ß2-microglobulin. Amyloid. Vol. 17(2): 50-62. 


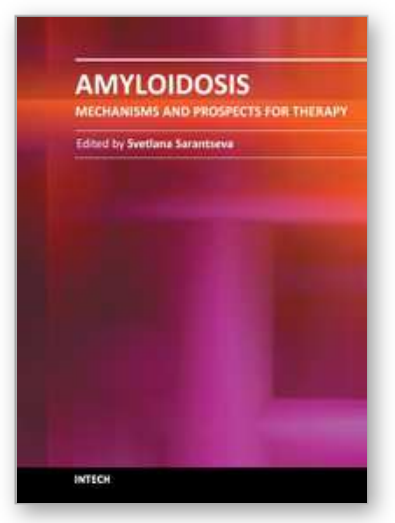

\author{
Amyloidosis - Mechanisms and Prospects for Therapy \\ Edited by Dr. Svetlana Sarantseva
}

ISBN 978-953-307-253-1

Hard cover, 216 pages

Publisher InTech

Published online 22, September, 2011

Published in print edition September, 2011

Amyloidoses are a heterogeneous group of diverse etiology diseases. They are characterized by an endogenous production of abnormal proteins called amyloid proteins, which are not hydrosoluble, form depots in various organs and tissue of animals and humans and cause dysfunctions. Despite many decades of research, the origin of the pathogenesis and the molecular determinants involved in amyloid diseases has remained elusive. At present, there is not an effective treatment to prevent protein misfolding in these amyloid diseases. The aim of this book is to present an overview of different aspects of amyloidoses from basic mechanisms and diagnosis to latest advancements in treatment.

\title{
How to reference
}

In order to correctly reference this scholarly work, feel free to copy and paste the following:

Keiichi Higuchi, Xiaoying Fu, Pengyao Zhang, Jinko Sawashita, Beiru Zhang, Jinze Qian, Wang Yaoyong and Masayuki Mori (2011). Mouse Models to Study Systemic Amyloidoses: Is Prion-Like Transmission a Common Pathogenic Mechanism?, Amyloidosis - Mechanisms and Prospects for Therapy, Dr. Svetlana Sarantseva (Ed.), ISBN: 978-953-307-253-1, InTech, Available from: http://www.intechopen.com/books/amyloidosismechanisms-and-prospects-for-therapy/mouse-models-to-study-systemic-amyloidoses-is-prion-liketransmission-a-common-pathogenic-mechanism-

\section{INTECH}

open science | open minds

\author{
InTech Europe \\ University Campus STeP Ri \\ Slavka Krautzeka 83/A \\ 51000 Rijeka, Croatia \\ Phone: +385 (51) 770447 \\ Fax: +385 (51) 686166 \\ www.intechopen.com
}

\author{
InTech China \\ Unit 405, Office Block, Hotel Equatorial Shanghai \\ No.65, Yan An Road (West), Shanghai, 200040, China \\ 中国上海市延安西路65号上海国际贵都大饭店办公楼 405 单元 \\ Phone: +86-21-62489820 \\ Fax: +86-21-62489821
}


(C) 2011 The Author(s). Licensee IntechOpen. This chapter is distributed under the terms of the Creative Commons Attribution-NonCommercialShareAlike-3.0 License, which permits use, distribution and reproduction for non-commercial purposes, provided the original is properly cited and derivative works building on this content are distributed under the same license. 